\title{
Impact of Asthma on the Quality of Life of Adolescent Patients from Saudi Arabia
}

\author{
Halwani $\mathbf{R}^{1,2^{*}}$, Al-kufeidy $\mathbf{R}^{1}$, Muharib BA ${ }^{1}$, Alkhashram FM ${ }^{1}$, Hussain SIB ${ }^{1}$, Alhenaki RS ${ }^{1}$, Vazquez-Tello A $^{1}$, Al-Frayh $^{2}$, Iqbal SM ${ }^{2}$ and Al-Muhsen $\mathbf{S}^{1,2}$ \\ ${ }^{1}$ Prince Naif Center for Immunology Research, College of Medicine, King Saud University, Riyadh, Saudi Arabia \\ ${ }^{2}$ Department of Pediatrics, College of Medicine, King Saud University, Riyadh, Saudi Arabia
}

"Corresponding author: Rabih Halwani, Prince Naif Center for Immunology Research, Asthma Research Chair, College of Medicine, King Saud University, P. O. Box 2925, Riyadh, 11461, Saudi Arabia, Tel: +966-1-4690146; Fax: +966-1-4679463; E-mail: rhalwani@ksu.edu.sa

Received date: August 02, 2016; Accepted date: August 30, 2016; Published date: August 31, 2016

Copyright: @ 2016 Halwani R, et al. This is an open-access article distributed under the terms of the Creative Commons Attribution License, which permits unrestricted use, distribution, and reproduction in any medium, provided the original author and source are credited.

\begin{abstract}
Background: Bronchial asthma is a chronic inflammatory disease afflicting people worldwide without distinction of age, gender or ethnicity. The health-related quality of life (HRQL) of adolescents with asthma can be disrupted considerably and may reflect the effectiveness of symptoms management, therapy and health services provided.

Objective: To evaluate the health-related quality of life (HRQL) of Saudi Arab adolescents with documented clinical history of asthma, classified by severity.

Methods: In this cross-sectional survey, the Pediatric Asthma Quality of Life (PAQLQ) and the Mini Asthma Quality of life (Mini-AQLQ) questionnaires were applied to 135 randomly recruited asthma patients (11-to-19 years old) in the period between January and June 2012, grouped as intermitent, mild, moderate, or severe.

Results: In 9 of 27 questions, significantly impaired HRQL was perceived by severe asthmatics, relative to intermittent patients; in particular, almost all aspects of the symptoms category significantly bothered the severe asthmatics. In emotional aspects, mild and moderates feel frustrated because couldn't keep up with others, whereas in social activities, moderate and severe groups indicated worse scores in school attendance, relative to intermittent asthmatics. In physical activities, severe and moderate groups reported lowest scores. A consistent finding was related to the influence of environmental triggers: Dust, cigarette smoke and air pollution impaired HRQL of all four asthma groups, relative to intermittent asthmatics.
\end{abstract}

Conclusion: Asthma lowers the health-related quality of life of Saudi adolescent patients, in terms of physical, emotional, symptoms, and environmental triggers, impairing mainly the severe asthmatics.

Keywords: Pediatric asthma; Teenagers; Asthma severity; Questionnaire; Quality of life score; Mini-AQLQ; PAQLQ

\section{Introduction}

Since the early 1960s, extensive epidemiological studies have confirmed the rise in asthma prevalence, morbidity and mortality rates in many countries and ethnic populations, thus becoming one of the most common chronic pulmonary diseases in the world [1,2]. Asthma affects not only the breathing capacity of patients, but also impacts their health-related quality of life (HRQL), as defined by the general well-being and happiness of the individual, in relation to physical, emotional and social aspects [3-5].

Quality of life questionnaires aim to collect data as accurate as possible, about a patient's symptoms and functioning on daily life. Such information could in turn be used by physicians and caregivers to evaluate the management of asthma and therapy efficacy [6-8]. In that view, many studies around the world have investigated how asthma affects HRQL of asthmatic patients. For instance, several studies have found that asthmatic teenager girls have lower HRQL perception than asthmatic boys; also, education about asthma disease and the proper use of medication play an important role [9-11]. In general, asthmatics have their daily life activities disrupted, such as attendance to workplace and school, as well as limiting their basic physical and social activities [10,12-14]. Furthermore, HRQL is more compromised in patients with refractory asthma or requiring oral steroids [15]. Reportedly, steroid-resistant asthmatics are significantly more predisposed to anxiety and depression than patients with well controlled symptoms, and experience fatigue, sleep disturbances and have a general feeling of frustration [16]. Therefore, higher rates of hospitalization, more frequent visits to the emergency department (ER), and poor HRQL self-assessment (e.g., reporting some restrictions in daily activities), are characteristic of this subgroup [17].

In Saudi Arabia, approximately $11 \%$ of the population (of which many are children and adolescents) suffers from this disease [18]. So far, no studies in Saudi Arabia have been done to investigate the impact of asthma on the HRQL of adolescents. Although similar surveys have been done in many countries, divergence in responses to medical treatment suggest important cultural, gender and socioeconomic differences; therefore, extrapolation of foreign results into another society is discouraged [19]. Indeed, the Saudi society has unique peculiarities, including linguistic, religious, cultural and health care setting different in relation to Western societes, which justify this work. In this cross-sectional survey, we interviewed adolescents with asthma from Saudi Arabia, by using the highly reliable and fully 
validated Pediatric Asthma Quality of Life questionnaire (PAQLQ) and the Mini Asthma Quality of life Questionnaire (MiniAQLQ) [6,13]. The goal was to evaluate the impact of asthma severity symptoms and environmental factors on the emotional, physical and social aspects of life of Saudi adolescent patients.

\section{Methods}

\section{Patients}

A total of 135 adolescents, aged 11-19 years old and clinically diagnosed with asthma and classified according to Guidelines by the Global Initiative for Asthma in adolescents (GINA) [20], were recruited at the Pediatric Asthma Clinic of the King Khalid University Hospital in Riyadh, Saudi Arabia in the period between January and June, 2012. Patients were randomly recruited at the time of their visit to the clinic, during a period spanning 10 months. All patients were evaluated by pulmonologists, who confirmed a documented clinical history of asthma and follow-up visits, and were classified into 4 asthma severity groups according to GINA guidelines: Intermittent, mild, moderate and severe [20]; because of the random recruitment, no effort was done to equalize the size's groups. Criteria of eligibility were: a) Be a Saudi citizen; b) Clinical history of at least one year of asthma; c) Aged from 11 to 19 years old. Patients were excluded if they presented other disorders or diseases, such as acute respiratory tract infections in the past two weeks, or if they were tobacco smokers. The study protocol was approved by the Institutional Review Board (IRB) of the college of Medicine, King Saud University. All patients and control subjects in this study signed an informed consent approved by the IRB.

\section{Study design and assessment of quality of life}

Patients were invited to participate in this survey and an informed written consent was signed from the parent/guardian before administering the questionnaire. The study protocol was approved by the Institutional Review Board (IRB) of the college of Medicine, King Saud University. Patients were interviewed individually, face to face, in a dedicated room whenever possible, to ensure confidentiality and privacy. The interviewer read the questions keeping in mind the comprehensive capability of the patient/subject; a pilot reliability test was also performed, using the entire questionnaire with a random sample of asthmatics $(n=12)$ to verify that they provided reliable answers. Both the PAQLQ and the Mini-AQLQ overlap in many questions; thus, the applied questionnaire contained all the questions of the Pediatric Asthma Quality of Life Questionnaire (PAQLQ) and complemented with the Mini-AQLQ, for questions pertaining to environmental triggers, which are absent in the PAQLQ [4,6,21]. Both questionnaires are highly reliable and well validated tools translated into many languages including Arabic, and cover the most important and bothersome aspects affecting the daily lives of asthmatics $[3,6,22]$. Taking into consideration that Saudi Muslims have distinct cultural, social activities and religious habits compared to Western countries, authors decided to include three exploratory, non-validated questions, to evaluate the potential negative impact of asthma on: a) The performance of their religious customs; b) Whether asthma would affect the choice of a career; and c) Whether asthma would affect their work efficiency.

\section{Statistical analysis}

HRQL score values for each question (variable) ranged from 1 (indicating maximum impairment) to 7 (no impairment at all) $[4,6]$. Both the mean scores and the total sums of scores for each question were calculated. The overall score, which is the mean of all responses per asthma severity group was also calculated. For each question item, to determine possible significant differences in HRQL mean scores among the four asthma severity groups, one-way ANOVA was performed; when significant differences were detected (two-tailed $\mathrm{P}<0.05)$, Dunnett's multiple comparison tests were performed by comparing the HRQL mean scores of the intermittent group versus those of the mild, moderate and severe groups. Equality of population variances was confirmed through Bartlett's tests in all cases. Further, a score analysis by categories (physical, emotional, social, symptoms, environmental) was performed: For each category, the HRQL scores of corresponding questions were summed up and the means calculated; to determine significant differences among the 4 asthma severity groups, one-way ANOVA tests were done; Dunnett's multiple comparison tests were performed by comparing the intermittent group's score versus those of the mild, moderate and severe asthma groups. Significant differences were considered at two-tailed $\mathrm{P}$ values $<0.05$ in all cases. Data were analyzed using SPSS and/or GraphPad Prism software packages.

\section{Results}

A total of 135 adolescents were recruited, which were asthma patients classified into intermittent, mild, moderate or severe groups. Principal demographic and clinical data of the recruited asthmatics are presented in Table 1. There were fewer severe asthmatics recruited, whereas the largest group corresponded to the intermittent asthmatics; because of the random recruitment procedure, no effort was made to equalize the sample size of each group. The age of all asthmatic patients averaged 14.6 years old (standard deviation of \pm 2.3 ); the majority were male students (58.5\%), attending secondary school (60.7\%).

\begin{tabular}{|c|c|c|c|c|c|c|}
\hline \multirow{2}{*}{ Patients } & \multirow{2}{*}{$\mathrm{Age}^{*}$} & \multirow{2}{*}{$\begin{array}{l}\text { Gender ratios } \\
\mathrm{M} / \mathrm{F}\end{array}$} & \multirow{2}{*}{ Total subjects (\%) } & \multicolumn{3}{|c|}{ Scholar Education } \\
\hline & & & & Primary & Secondary & High-School \\
\hline Intermitent & $14.5 \pm 2.2$ & $29 / 19$ & $48(35.5)$ & 13 & 31 & 4 \\
\hline Mild-persistent & $14.7 \pm 2.2$ & $27 / 15$ & $42(31.1)$ & 9 & 30 & 3 \\
\hline Moderate-persistent & $14.0 \pm 2.4$ & 17-Aug & $25(18.5)$ & 9 & 13 & 3 \\
\hline Severe-persistent & $15.3 \pm 2.3$ & Jun-14 & $20(14.8)$ & 5 & 8 & 7 \\
\hline
\end{tabular}

Table 1: Characteristics and frequencies of the recruited adolescent asthmatic patients. 
Citation: Halwani R, Al-kufeidy R, Muharib BA, Alkhashram FM, Hussain SIB, et al. (2016) Impact of Asthma on the Quality of Life of Adolescent Patients from Saudi Arabia. Lung Dis Treat 2: 114. doi:10.4172/2472-1018.1000114

Page 3 of 6

\begin{tabular}{|c|c|c|c|c|c|c|}
\hline \multirow{3}{*}{ Category } & \multirow{3}{*}{ Variables§ } & \multicolumn{4}{|c|}{$\ddagger$ HRQL scores by groups } & \multirow[t]{3}{*}{ "P values } \\
\hline & & \multirow{2}{*}{ Intermittent } & Mild & Moderate & Severe & \\
\hline & & & Persistent & persistent & persistent & \\
\hline \multirow{4}{*}{ Physical activities } & Q1. Strenuous activities & 3.5 & 3.3 & 3 & 3.1 & 0.529 \\
\hline & Q2. Moderate activities & 2.6 & 2.9 & 2.4 & 3 & 0.475 \\
\hline & $\begin{array}{l}\text { Q3. Couldn't keep up with } \\
\text { others }\end{array}$ & 4.4 & 5 & 4.3 & 3.9 & 0.15 \\
\hline & Q4. School-related activities & 2.9 & 3.4 & 2.8 & $3.7^{(1)}$ & $0.004^{*}$ \\
\hline \multirow{7}{*}{ Emotional aspects } & Q5. Feel frustrated & 6.1 & 5.8 & 5.4 & 5.2 & 0.519 \\
\hline & $\begin{array}{l}\text { Q6. Feel afraid of not having } \\
\text { asthma medication available }\end{array}$ & 5.6 & 6 & $4.8^{(1)}$ & $5.0^{(1)}$ & $0.04^{*}$ \\
\hline & $\begin{array}{l}\text { Q7. Feel worried, concerned } \\
\text { or troubled }\end{array}$ & 5.5 & 5.2 & 5.2 & 5.1 & 0.364 \\
\hline & Q8. Feel angry & 5.6 & 4.9 & 5.4 & 4.4 & 0.119 \\
\hline & Q9. Feel different or left out & 6.6 & $5.8^{(1)}$ & 6.6 & 6.2 & 0.05 \\
\hline & $\begin{array}{l}\text { Q10. Feel frustrated because } \\
\text { couldn't keep up with others }\end{array}$ & 6.5 & $5.2^{(1)}$ & $5.3^{(1)}$ & 5.6 & $0.031^{*}$ \\
\hline & $\begin{array}{l}\text { Q11. Feel frightened by an } \\
\text { asthma attack }\end{array}$ & 5.1 & 4.5 & 4.5 & 4 & 0.423 \\
\hline \multirow{8}{*}{ Asthma Symptoms } & $\begin{array}{l}\text { Q12. How much did coghing } \\
\text { bothered you }\end{array}$ & 5 & 3 & 3.7 & $2.4^{(1)}$ & $0.021^{*}$ \\
\hline & $\begin{array}{l}\text { Q13. How much did } \\
\text { shortness of breath bothered } \\
\text { you }\end{array}$ & 3.4 & $2.4^{(1)}$ & 2.9 & $2.1^{(1)}$ & $0.015^{*}$ \\
\hline & $\begin{array}{l}\text { Q14. How much did chest } \\
\text { tightness or chest heaviness } \\
\text { bothered you }\end{array}$ & 4.4 & 3.4 & 3.7 & $3.0^{(1)}$ & $0.050^{*}$ \\
\hline & $\begin{array}{l}\text { Q15. How often did you have } \\
\text { trouble getting a good night's } \\
\text { sleep }\end{array}$ & 4.6 & 4.4 & 4.7 & 3.9 & 0.403 \\
\hline & $\begin{array}{l}\text { Q16. How much did } \\
\text { wheezing bother you }\end{array}$ & 4 & 4.3 & 3 & $2.8^{(1)}$ & $0.014^{*}$ \\
\hline & $\begin{array}{l}\text { Q17. How often did your } \\
\text { asthma wake up at night }\end{array}$ & 5 & $4.0^{(1)}$ & 4.4 & $2.9^{(1)}$ & $0.031^{*}$ \\
\hline & $\begin{array}{l}\text { Q18. How often did you feel } \\
\text { out of breath }\end{array}$ & 5.4 & 4.9 & 4.6 & $3.3^{(1)}$ & $0.004^{*}$ \\
\hline & $\begin{array}{l}\text { Q19. How often did you have } \\
\text { difficulty taking a deep breath }\end{array}$ & 4.5 & 3.7 & 4.3 & 3.3 & 0.094 \\
\hline \multirow[b]{2}{*}{ Environmental factors } & $\begin{array}{l}\text { Q20. Feel bothered by or } \\
\text { have to avoid dust }\end{array}$ & 3 & 2.4 & 2.1 & 2 & 0.059 \\
\hline & $\begin{array}{l}\text { Q21. Feel bothered by or } \\
\text { have to avoid cigarette } \\
\text { smoke }\end{array}$ & 2.7 & 2.6 & 2.6 & 2.7 & 0.995 \\
\hline
\end{tabular}




\begin{tabular}{|c|c|c|c|c|c|c|}
\hline & $\begin{array}{l}\text { Q22. Feel bothered by or } \\
\text { have to avoid going outside } \\
\text { because of weather or air } \\
\text { pollution }\end{array}$ & 3.7 & 4.2 & 3 & 3.1 & 0.145 \\
\hline \multirow{5}{*}{ Social activities } & $\begin{array}{l}\text { Q23. How limited have you } \\
\text { been doing social activities }\end{array}$ & 2.5 & 2.9 & 3 & 4.1 & 0.069 \\
\hline & $\begin{array}{l}\text { Q24. How often did asthma } \\
\text { prevent you from going to } \\
\text { school }\end{array}$ & 5 & 4.4 & $3.8^{(1)}$ & $3.5^{(1)}$ & $0.012^{\star}$ \\
\hline & $\begin{array}{l}\text { Q25. How often did asthma } \\
\text { prevent you from performing } \\
\text { your religious duties }\end{array}$ & 6.3 & 5.7 & 6.2 & 6.1 & 0.386 \\
\hline & $\begin{array}{l}\text { Q26. Feel that asthma will } \\
\text { affect your choice of a career }\end{array}$ & 6.1 & 5.6 & 6 & 6.2 & 0.483 \\
\hline & $\begin{array}{l}\text { Q27. Feel that asthma will } \\
\text { affect your working efficiency }\end{array}$ & 6.3 & $5.3^{(1)}$ & 6 & 6.2 & $0.024^{*}$ \\
\hline \multicolumn{2}{|l|}{ Overall scores } & 4.7 & 4.3 & 4.2 & 3.9 & 0.211 \\
\hline
\end{tabular}

Table 2: Comparative analysis of HRQL mean scores by questions among asthma severity groups.

Table 2 shows a comparative analysis of the impact of asthma on HRQL scores from patients classified in four different severity groups. Multiple pairwise comparisons between the intermittent group versus mild, moderate and severe asthma revealed significant differences in 13 out of 27 questions; most of them (9 questions) confirmed that severe asthmatics (and sporadically moderate and mild asthmatics) perceived their HRQL as more adversely affected in relation to intermittent patients. This was particularly consistent in questions of the asthma symptoms category: The aspects that bothered significantly the severe asthmatics more than intermittent asthmatics were coughing (Q12), shortness of breath (Q13), chest tightness (Q14), wheezing (Q16), night wakeups (Q17) and feel out of breath (Q18). In contrast, in two particular questions, Q4 (school-related activities) and Q23 (social activities), the results were the opposite, in the sense that the severe group reported significantly better scores than the other groups with milder symptoms. Regarding the overall scores, quantitative differences greater than 0.5 in the 7-points scale, between intermittent (4.7) and moderate (4.2) and severe (3.9) groups were observed; although they were not statistically significant (ANOVA, P value $=0.211$ ), differences of such magnitude are considered clinically important [23].

The questions are listed in short form for the sake of space, keeping the essential keywords. Overall scores: The mean of all responses per asthma severity groups. *One-way ANOVA P values. Significance was considered at two-tailed $\mathrm{P}<0.05$. $\ddagger$ Dunnett's post-hoc tests, where scores from mild, moderate and severe groups marked with ${ }^{(1)}$ and highlighted with bold font were significantly different than those of intermittent group.

The data were also analyzed by categories, in which the HRQL mean sum of scores of the mild, moderate and severe groups were compared to those of the intermittent group (Table 3). This test found significant differences only within the symptoms category, indicating that the mild, moderate and severe groups of patients had a worse perception of their HRQL than that of the intermittent patients.

\begin{tabular}{|c|c|c|c|c|c|}
\hline \multirow{2}{*}{ Categories } & \multicolumn{4}{|c|}{$\ddagger$ HRQL Mean Sum scores \pm SDev } & \multirow{2}{*}{$\begin{array}{l}\text { *P- } \\
\text { values } \\
-1\end{array}$} \\
\hline & Intermittent & Mild & Moderate & Severe & \\
\hline $\begin{array}{l}\text { Physical } \\
\text { activities }\end{array}$ & $8.95 \pm 3.36$ & $\begin{array}{ll}9.66 & \pm \\
3.94 & \end{array}$ & $8.28 \pm 3.53$ & $9.9 \pm 5.27$ & 0.424 \\
\hline $\begin{array}{l}\text { Emotional } \\
\text { aspects }\end{array}$ & $41.02 \pm 8.03$ & $\begin{array}{ll}37.42 & \pm \\
8.24 & \end{array}$ & $\begin{array}{ll}37.2 & \pm \\
10.55 & \end{array}$ & $\begin{array}{ll}35.4 & \pm \\
10.77 & \end{array}$ & 0.071 \\
\hline $\begin{array}{l}\text { Asthma } \\
\text { Symptoms }\end{array}$ & $34.93 \pm 8.8$ & $\begin{array}{l}29.83 \pm \pm \\
10.15^{(1)}\end{array}$ & $\begin{array}{ll}30.72 & \pm \\
9.14 & \end{array}$ & $\begin{array}{l}23.35 \\
9.46^{(1)}\end{array} \quad \pm$ & $0.0001^{*}$ \\
\hline $\begin{array}{l}\text { Environmenta } \\
\text { I factors }\end{array}$ & $9.41 \pm 5.24$ & $\begin{array}{ll}9.16 & \pm \\
4.81 & \end{array}$ & $7.72 \pm 3.98$ & $7.7 \pm 5.24$ & 0.34 \\
\hline $\begin{array}{l}\text { Social } \\
\text { activities }\end{array}$ & $26.25 \pm 4.36$ & $\begin{array}{ll}23.81 \quad \pm \\
5.06\end{array}$ & $25.0 \pm 5.5$ & $\begin{array}{ll}26.05 & \pm \\
6.6 & \end{array}$ & 0.139 \\
\hline \multicolumn{6}{|c|}{$\begin{array}{l}\text { "One-way ANOVA P values; } ¥ \text { Dunnett's post-hoc tests; scores from mild } \\
\text { moderate and severe groups marked with }{ }^{(1)} \text { and highlighted with bold font were } \\
\text { significantly different than those of intermittent group. Significance was } \\
\text { considered at two-tailed } \mathrm{P}<0.05\end{array}$} \\
\hline
\end{tabular}

Table 3: Comparative analysis of HRQL sums of scores by categories.

\section{Discussion}

Asthma disease can result in varying degrees of restrictions in a patient's life, perceived in general as a lower quality of life which includes physical, emotional and social aspects $[6,8,9,13,15]$. Although many studies around the world have been conducted in order to evaluate the impact of asthma on HRQL aspects of life [15,17,24,25], in Saudi Arabia, analyses on the quality of life of adolescents with different asthma severity symptoms are lacking. 
This study identified a number of questions from different categories with better sensitivity at detecting HRQL score differences among the asthma groups. In general, (with two exceptions mentioned) the detrimental effect of asthma on HRQL appeared to be a function of its severity: Severe persistent asthmatics tended to be more sensitive to environmental triggers, prone to disrupting schooling activities, limiting strenuous physical activities (e.g., sports) and complaining of many symptoms causing discomfort, in relation to other asthma groups.

Specifically, regarding physical aspects, scores for strenuous activities (Q1) but not moderate activities (Q2) were diminished by asthma in severe and moderate asthmatics, whereas mild and intermediate asthmatics reported equivalent scores. Possibly, severe and moderate asthmatics avoid strenuous exercise for fear of triggering an exacerbation [26]. In contrast, the intermittent and mild asthmatics do practice strenuous physical activities more frequently, suggesting that their milder symptoms may not bother them enough. This is supported by the lack of significant differences in Q2 (moderate activities) and Q3 (couldn't keep up with others). In this respect, a Portuguese team reported similarities in sedentary lifestyles between adult asthmatics and healthy subjects: Depending on whether adult male and female asthmatics achieved control of symptoms, these patients did as much moderate and vigorous physical activities as healthy subjects [27]. As an alternative explanation, some reports have indicated that asthmatic children often express denial at their inability to have a normal life; for instance, some adolescents may have a 'risky' behaviour, by forcing themselves to act 'normally', trying to fit with their peers in order to avoid exclusion or ostracism [28].

Regarding the impact of asthma on emotional aspects, our study found that severe, moderate and mild groups were significantly affected in relation to intermittent asthmatics. In particular, severe and moderate groups were worried about not having their medication (Q6), whereas mild and moderate patients reported to feel frustrated because couldn't keep up with others (Q10). These finding contrasts with other reports that found no correlation of HRQL scores with emotional factors and that anxiety or depression do not always associate with asthma $[10,29]$. Nevertheless, other investigators have confirmed that exacerbations are truly detrimental to HRQL $[3,9,15]$.

Furthermore, this study found that environmental factors such as dust, smoke and air pollution exert an important effect, by consistently lowering HRQL scores of all asthmatics; even though no significant differences among the asthma groups were found, the observed trend is to lower the scores, suggesting that these environmental triggers could be bothersome for asthmatics. In fact, dust allergens are considered a major environmental issue in Saudi Arabia [30].

Regarding social activities that were restricted by asthma, school attendance (Q24) scores were significantly worse in moderate and severe patients, comparatively to intermittent asthmatics. However, the severe asthma group not always reported the worse scores; in one particular variable, limitation in performing social activities as a result of asthma (Q23), this group of patients reported significantly better scores than the intermittent. Such unrestriction contrasts with observations in childhood asthma; for instance in children from the Netherlands, several social aspects were negatively influenced by asthma, and bullying by their peers was also reported [31]. It has been argued that some asthma patients see themselves as leading normal lives, but this could be a biased perception influenced by adjustments in their lifestyles imposed by disease [32]. In addition, by including three exploratory non-validated questions, this study revealed that asthma does not affect significantly the performance of their religious duties, nor induce concerns about their future job or career. Congruent with these observations, a study from the Netherlands reported similar HRQL scores between asthma adolescents and a reference control group, in relation to self-reported psychosocial problems [33]. Another study from the United States also failed to find significant differences on all psychosocial aspects between young asthma adult patients and those with no chronic condition [34]. Evidently, asthma as a disease may not be a major factor limiting the social life of Saudi adolescents; this is congruent with reported changes in behaviour of adolescent patients, who deny the seriousness of their disease, perhaps because they fear to be perceived differently from others [35]. In turn, such 'abnormal' behaviour could represent an obstacle in the diagnosis and management of the disease [36].

\section{Limitations and Future Research}

Although valuable information was obtained directly from the patients, and our main objective was achieved, potential shortcomings in this study need to be addressed in the future. A characteristic of the Saudi society is the practice of gender segregation, with women facing restricted rights and inequalities in comparison to other countries of the Middle East [37]; in contrast to men, for which there are no restrictions in physical exercise or social activities, women have mobility restrictions and limited or nil access to sport facilities. Therefore, since a predominance of female teenagers over males were recruited in the severe groups, relative to the intermittent, mild and moderate groups, we cannot exclude the possibility that this difference could have influenced HRQL scores. Another limitation of this survey is that it was not possible to collect information about their asthma control status. Further research should focus on gender differences, by comparing HRQL of women and men in relation to asthma, and to identify and characterize risk factors with greatest impact on HRQL and how such factors could be prevented and managed. These findings could help suggesting improvements on the Saudi medical system and to direct health practitioners on ways to manage symptoms, so as to improve the quality of life of patients.

\section{Conclusion}

This study showed that asthma lowers significantly the quality of life of Saudi asthmatic adolescents in several aspects, with environmental, emotional and physical activities as being particularly influenced. We postulate that lack of symptoms control in intermittent and mild asthmatics, contributes to lower HRQL perception; this hypothesis deserves further analysis in the future.

\section{Acknowledgement}

This work was supported by the Deanship of Scientific Research at King Saud University, Riyadh, Saudi Arabia.

\section{Disclosure}

All authors declare to have no financial support that may pose conflicts of interest in relation to this article.

\section{Author Contribution}

RK, BAM, FM, SIH, RSA were responsible for the execution of the study, interviewing patients and subjects, collection of data, and performed a preliminary analysis and report. AVT performed the 
compilation of data, statistical analyses, and wrote the manuscript. AF, MMS, SMI, SM, participated in the initial phase of planning and design of the study, and analyzed the clinical history of the recruited patients. RH was the main coordinator responsible in the design, planning and reviewing of the preliminary report and final manuscript. All authors read and approved the final manuscript.

\section{References}

1. De Sario M, Katsouyanni K, Michelozzi P (2013) Climate change, extreme weather events, air pollution and respiratory health in Europe. Eur Respir J 42: 826-843.

2. Bousquet J, Khaltaev N, Cruz AA, Denburg J, Fokkens WJ, et al. (2008) Allergic rhinitis and its impact on asthma (ARIA). Allergy 63: 8-160.

3. Juniper EF, Guyatt GH, Feeny DH, Ferrie PJ, Griffith LE, et al. (1996) Measuring quality of life in children with asthma. Qual life Res 5: 35-46.

4. Reichenberg K, Broberg AG (2000) Quality of life in childhood asthma: use of the Paediatric Asthma Quality of Life Questionnaire in a Swedish sample of children 7 to 9 years old. Acta Paediatr 89: 989-995.

5. Moy ML, Israel E, Weiss ST, Juniper EF, Dube L, et al. (2001) Clinical predictors of health-related quality of life depend on asthma severity. Am J Respir Crit Care Med 163: 924-929.

6. Juniper EF, Guyatt GH, Cox FM, Ferrie PJ, King DR (1999) Development and validation of the mini asthma quality of life questionnaire. Eur Respir J 14: 32-38.

7. Leidy NK, Chan KS, Coughlin C (1998) Is the asthma quality of life questionnaire a useful measure for low-income asthmatics?. Am J Respir Crit Care Med 158: 1082-1090.

8. Osman LM, Calder C, Robertson R, Friend JA, Legge JS, et al. (2000) Symptoms, quality of life, and health service contact among young adults with mild asthma. Am J Respir Crit Care Med 161: 498-503.

9. Forrest CB, Starfield B, Riley AW, Kang M (1997) The impact of asthma on the health status of adolescents. Pediatrics 99: 1-7.

10. Kolawole MS, Olayemi AF, Gregory EE, Abiodun AO, Daniel OO, et al. (2011) Health related quality of life and psychological variables among a sample of asthmatics in Ile-Ife South-Western Nigeria. Libyan J Med 6.

11. Nogueira KT, Silva JRL, Lopes CS (2009) Quality of life of asthmatic adolescents: assessment of asthma severity, comorbidity, and life style. Jornal de Pediatria 85: 523-530.

12. Kiotseridis H, Cilio CM, Bjermer L, Aurivillius M, Jacobsson H, et al. (2013) Quality of life in children and adolescents with respiratory allergy, assessed with a generic and disease-specific instrument. Clin Respir J 7: 168-175.

13. Moreira H, Carona C, Silva N, Frontini R, Bullinger M, et al. (2013) Psychological and quality of life outcomes in pediatric populations: a parent-child perspective. J Pediatrics 163: 1471-1478.

14. Basso RP, Jamami M, Labadessa IG, Regueiro EMG, Pessoa BV, et al. (2013) Relationship between exercise capacity and quality of life in adolescents with asthma. Jornal Brasileiro de Pneumologia 39: 121-127.

15. Lloyd A, Price D, Brown R (2007) The impact of asthma exacerbations on health-related quality of life in moderate to severe asthma patients in the UK. Prim Care Respir J 16: 22-27.

16. Rand CS, Butz AM, Kolodner K, Huss K, Eggleston P, et al. (2000) Emergency department visits by urban African American children with asthma. J Allergy Clin Immunol 105: 83-90.

17. Rosenman S, Rodgers B (2004) Childhood adversity in an Australian population. Soc Psychiatry Psychiatr Epidemiol 39: 695-702.
18. Al Frayh AR, Shakoor Z, ElRab MG, Hasnain SM (2001) Increased prevalence of asthma in Saudi Arabia. Ann Allergy Asthma Immunol 86 292-296.

19. Ståhl E, Postma DS, Juniper EF, Svensson K, Mear I, et al. (2003) Healthrelated quality of life in asthma studies. Can we combine data from different countries? Pulm Pharmacol Ther 16: 53-59.

20. Bateman E, Hurd SS, Barnes PJ, Bousquet J, Drazen JM, et al. (2008) Global strategy for asthma management and prevention: GINA executive summary. Eur Respir J 31: 143-178.

21. Juniper EF, Guyatt GH, Epstein RS, Ferrie PJ, Jaeschke R, et al. (1992) Evaluation of impairment of health related quality of life in asthma: development of a questionnaire for use in clinical trials. Thorax 47: 76-83.

22. Abdel Hai R, Taher E, Fattah MA (2010) Assessing validity of the adapted Arabic Paediatric Asthma Quality of Life Questionnaire among Egyptian children with asthma. East Mediterr Health J 16: 274-280.

23. Juniper EF, Gruffydd-Jones K, Ward S, Svensson K (2010) Asthma Control Questionnaire in children: validation, measurement properties, interpretation. Eur Respir J 36: 1410-1416.

24. Wilson SR, Rand CS, Cabana MD, Foggs MB, Halterman JS, et al. (2012) Asthma outcomes: quality of life. J Allergy Clin Immunol 129: S88-S123.

25. Merikallio VJ, Mustalahti K, Remes ST, Valovirta EJ, Kaila M (2005) Comparison of quality of life between asthmatic and healthy school children. Pediatr Allergy Immunol 16: 332-340.

26. DiDario AG, Becker JM (2005) Asthma, sports, and death. Allergy Asthma Proc 26: 341-344.

27. Verlaet A, Moreira A, Sá-Sousa A, Barros R, Santos R, et al. (2013) Physical activity in adults with controlled and uncontrolled asthma as compared to healthy adults: a cross-sectional study. Clin Transl Allergy 3: 1 .

28. Rich M, Taylor SA, Chalfen R (2000) Illness as a social construct: understanding what asthma means to the patient to better treat the disease. Jt Comm J Qual Patient Saf 26: 244-253.

29. Janson C, Björnsson E, Hetta J, Boman G (1994) Anxiety and depression in relation to respiratory symptoms and asthma. Am J Respir Crit Care Med 149: 930-934.

30. Almogren A (2009) Airway allergy and skin reactivity to aeroallergens in Riyadh. Saudi Med J 30: 392-396.

31. vanden Bemt L, Kooijman S, Linssen V, Lucassen P, Muris J, et al. (2010) How does asthma influence the daily life of children? Results of focus group interviews. Health Qual Life Outcomes 8: 5.

32. Van Gent R, Essen-Zandvliet EEM, Klijn P, Brackel HJL, Kimpen JLL, et al. (2008) Participation in daily life of children with asthma. J Asthma 45: 807-813.

33. Tibosch M, Reidsma C, Landstra A, Hugen C, Gerrits P, et al. (2010) An asthma-related quality of life instrument is unable to identify asthmatic children with major psychosocial problems. Eur J Pediatr 169: 1495-1501.

34. Berge JM, Bauer KW, Eisenberg ME, Denny K, Neumark-Sztainer D (2012) Psychosocial and health behavior outcomes of young adults with asthma or diabetes. J Community Med Health Educ 2: 144.

35. Sadof M, Kaslovsky R (2011) Adolescent asthma: a developmental approach. Curr Opin Pediatr 23: 373-378.

36. Rietveld S, Creer TL (2003) Psychiatric factors in asthma: implications for diagnosis and therapy. Am J Respir Med 2: 1-10.

37. Mobaraki AEH, Söderfeldt B (2010) Gender inequity in Saudi Arabia and its role in public health/L'inégalité entre hommes et femmes en Arabie saoudite et ses conséquences sur la santé publique. East Mediterr Health J 16: 113-118. 